Acta Theriologica 42 (3): 313-320, 1997.

PL ISSN 0001-7051

\title{
Sex differences in time budgeting in roe deer during the rut
}

\author{
Anthony P. F. FLINT and Andrzej KRZYWINSSKI
}

Flint A. P. F. and Krzywiński A. 1997. Sex differences in time budgeting in roe deer during the rut. Acta Theriologica 42: 313-320.

In a forest population of roe deer Capreolus capreolus (Linnaeus, 1758) studied in eastern Poland during the rut, does spent a greater proportion of time feeding and selecting food than bucks, during the dawn and dusk periods of grazing on meadows at the forest boundary. Bucks spent a greater proportion of time in movement (walking and running) and in orientation. These differences occurred at 3 of 4 study sites, and were unaffected by occurrence of social interactions. Although these findings contradict previous data they are predictable on the basis of optimal resource utilization, female reproductive success being determined by access to food, male reproductive success by access to mates.

Department of Physiology and Environmental Science, University of Nottingham, Sutton Bonington Campus, Loughborough, Leics LE12 5RD, UK, fax: 01159516302 , e-mail: Anthony.Flint@Nottingham.ac.uk (APFF); Deer Farm, Institute of Parasitology PAS, 11-730 Kosewo, Poland (AK)

Key words: Capreolus capreolus, rut, time budgeting

\section{Introduction}

Optimal resource use suggests male and female behaviours will differ during the mating season in a species in which access to females is disputed by males. Under these conditions female reproductive success is determined by access to food while male success depends on access to females, for which males compete (Bateman 1948, Trivers 1972). Females should therefore spend less time than males in the acquisition or defence of mates, regardless of whether the males are territorial. Red deer Cervus elaphus behaviour during the rut supports this prediction; stags spend less than $5 \%$ of the day grazing and ruminating, whereas hinds spend more than $40 \%$ of their time in these activities (Clutton-Brock et al. 1982). In moose Alces alces cows spend 50\% or more of the time feeding during the rut, while bulls spend less than 10\% (Miquelle 1990).

In roe deer Capreolus capreolus (Linnaeus, 1758) the mating system is characterized as territorial defence polygyny. Breeding males aggressively defend territories which overlap with or in some cases encompass one or more female home ranges (Bramley 1970, Strandgaard 1972a). Male access to mates is therefore dependent on territorial behaviour and a buck's ability to monopolize does depends on the exclusion of other bucks (including non-territorial bucks: Bramley 1970, 
Loudon 1978) from his territory. Under these conditions bucks would be expected to put more effort into territorial defence than does.

Contrary to theory, the available data suggest that roe deer bucks and does spend equal proportions of time in the principal activities recorded, including social interactions. In a study of roe deer in an open agricultural habitat, Turner (1979) found no differences between the sexes in time spent during the rut in orienting (observing the surroundings), searching (for food items), walking, feeding or in social interactions. Furthermore, data on weight loss during the rut suggest that if a reduction in time spent feeding occurs it may be quantitatively comparable in both sexes. Ellenberg (1978), studying enclosed roe deer showed that does and bucks reduce food intake and lose body weight to approximately equal extents during the rut, and similar observations were recorded by Barth et al. (1976) and Eisfeld (1977). In a study of roe deer activity using radio tracking, Cederlund (1981) recorded a decrease in time spent feeding during the rut in bucks, and a concomitant increase in movement (walking and running); unfortunately, comparable data were unavailable for does.

As the available data are difficult to reconcile with expectations, we investigated time budgeting in roe bucks and does during the rut. Specifically, the objective was to test the hypothesis that bucks spend less time feeding than does.

\section{Methods}

\section{Study area}

The study area, in the Mazurian Lakes region of north-eastern Poland (approx $53^{\circ} 50^{\prime} \mathrm{N} 21^{\circ} 20^{\prime} \mathrm{E}$ ), comprised mixed deciduous/coniferous forest with hay meadows, some of which were grazed by cattle. In each case observations were made from elevated hunting hides erected and maintained by the local Forestry Administration Unit. The hides allowed a field of view of at least $180^{\circ}$ and in one case $270^{\circ}$, and the total length of forest/pasture boundary observed was approximately $4 \mathrm{~km}$. No hunting had taken place in the area during the 10 months preceding the study. To reduce any error arising from the repeated observation of the same animal, four study locations were used, and they were chosen so as to be sufficiently far apart to ensure they were in separate territories (Bramley 1970, Sempéré 1979). The study sites were visited in random order. Sites A, B and C were each approximately $6 \mathrm{~km}$ from D; distances between $\mathrm{A}$ and $\mathrm{B}, \mathrm{B}$ and $\mathrm{C}$, and $\mathrm{A}$ and $\mathrm{C}$ were $1.3,0.74$ and $1.2 \mathrm{~km}$ respectively. Site D was crossed by a track used by local inhabitants and was potentially more prone to disturbance by man than sites $\mathrm{A}-\mathrm{C}$.

\section{Behavioural recording}

Observations were made between 30 July and 12 August 1991. Rutting occurred during the study period as confirmed by observing mating. A total of 81 sightings of roe deer were made during this period; data from 25 of these were excluded from analysis because the sex of the animals was not established, because they were fawns or because they were continuously visible for less than $1 \mathrm{~min}$ (the time required to obtain a representative value for time spent in different behaviours). All records were made by the same 2 observers working concurrently in the same hide. Roe deer inhabiting forest leave the cover of trees during periods of peak activity at dawn and dusk to feed on adjacent fields or meadows (Byron 1981, Aulak and Babińska-Werka 1990, Jeppesen 1989, 1990). Continuous visual recording of behaviour is seldom possible as these animals are difficult to observe while in forested 
areas, and therefore the data reported here were collected when the animals could be observed outside the cover of the forest. Roe deer were observed to leave the forest to feed on pastures viewed from the hides between $04.20-06.11 \mathrm{hr}$ and $19.04-21.19 \mathrm{hr}$. Behaviours of individual animals were noted at $10 \mathrm{sec}$ intervals ('Instantaneous Sampling' - Martin and Bateson 1993) by stop watch. The following behaviours were recorded (after Turner 1979): searching for or selecting food items while feeding (S), actively feeding (with head down, F), orienting (observing surroundings with head up, Or), walking $(\mathrm{W})$, running $(\mathrm{R})$, and 'other' (principally copulating, suckling or sniffing young at foot, scratching, lying, sniffing the air or the ground, chasing one another or marking undergrowth). For each of the 23 bucks and 33 does for which data were analysed, a total of 1135 analysed 10 sec recordings were made of behaviour of bucks, 1755 of does. Animals described below were observed for a total of $8 \mathrm{hr}$ 2 min (occasionally more than one animal was observed at any one time and data were collected concurrently). Numbers of $10 \mathrm{sec}$ records were not normally distributed, 7 individual animals being observed for periods between 20 and $45 \mathrm{~min}$; excluding these data did not affect the conclusions.

\section{Data analysis}

Numbers of observations in the 6 categories of behaviour listed above: F, S, W, Or, R and 'other', were summed and expressed as percentages of the total number of observations for that individual, to give the allocation of time to each behaviour as a percentage of the observation period, for each animal separately. Values for $\mathrm{F}$ and $\mathrm{S}, \mathrm{W}$ and $\mathrm{R}$ were summed. Times spent $\mathrm{F}+\mathrm{S}$, Or and $\mathrm{W}+\mathrm{R}$ were tested for differences due to sex, location or the presence of another individual. Details of statistical tests are given in the text. In all cases tests were based on numbers of animals, not numbers of observations. Data expressed as percentages were normalized by arcsin transformation where appropriate. There were no differences between dawn and dusk in the lengths of time for which individual animals were observed, and no differences in behaviour were noted between dawn and dusk for either does or bucks. Data obtained at dawn and dusk were therefore pooled for analysis.

Bucks were identified by presence of antlers. To the extent that the spikes of a yearling buck may be difficult to identify under some conditions there was potential for misidentification of yearling males as females. However, as the behaviour of yearling males resembles that of adult bucks (Bramley 1970, Turner 1979), this would obscure any difference between does and bucks, rather than contribute to it. If this error occurred it would therefore not invalidate the conclusion that there is a difference between the behaviours of adult males and females.

\section{Results}

Male and female time budgets differed significantly during the rut (Kruskal-Wallis 1 way ANOVA, $p<0.001$ ). Time spent feeding and searching for food items $(\mathrm{F}+\mathrm{S})$ was higher in does than in bucks, and does spent less time orienting (Or) and moving $(\mathrm{W}+\mathrm{R})$ than $\mathrm{F}+\mathrm{S}$ (Fig. 1). Based on all values for individual does (n $=33$ ) and bucks $(n=23)$, median values for $\mathrm{F}+\mathrm{S}$ were: bucks $30 \%$, does $71 \%$ (Mann-Whitney rank sum test, $p<0.001$ ). Corresponding values for Or were: bucks $29 \%$, does $19 \%$ ( $p<0.03)$; for $\mathrm{W}+\mathrm{R}$ : bucks $20 \%$, does $8 \%(p<0.005)$.

To determine whether time budgets were affected by social interactions, data where animals were observed concurrently were analysed separately (Table 1). Two or more deer were observed together on 18 occasions. On 12 of these a buck and a doe, or 3 or more individuals of both sexes were observed; on 5 occasions a doe was accompanied by a suckled fawn or yearling, and on one occasion 2 does were observed simultaneously. When a doe and a buck were observed together, 
Feeding + Searching

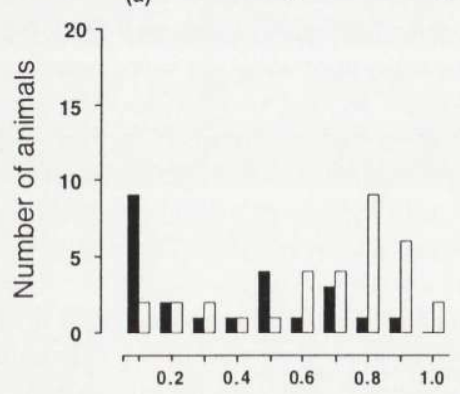

(b)

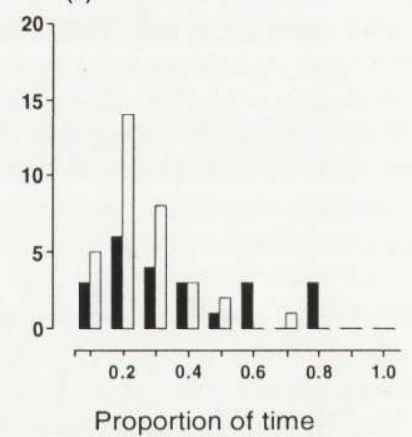

(c)

Walking + Running

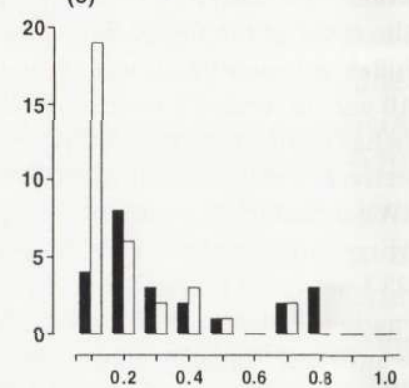

Fig. 1. Proportion of time spent (a) feeding + searching $(\mathrm{F}+\mathrm{S})$, (b) orienting $(\mathrm{Or})$, (c) walking + running $(\mathrm{W}+\mathrm{R})$. Histograms show numbers of animals with behaviours in intervals $0-10 \%, 11-20 \%$ etc of the observation period. Solid bars - bucks, open bars - does. See text for statistical analysis.

observation ended when a buck chased a doe out of sight (into cover of trees) on 9 of the 12 occasions. Once the encounter ended with mating, whereafter both animals walked into the forest. As shown in Table 1, whether chases occurred or not does spent more time $\mathrm{F}+\mathrm{S}$ and less time Or than bucks. Two-way repeated measures ANOVA with groups as subject and chase/no chase and sex as factors showed no statistically significant differences between the chase and no chase groups $(p>0.1$ ); differences between bucks and does, $p<0.05$ for $\mathrm{F}+\mathrm{S}$ and Or; for $\mathrm{W}+\mathrm{R}, p>0.1$ (chase and no chase groups pooled). However, there were no differences between those groups where there was a chase, and those where there was none, in times spent $\mathrm{F}+\mathrm{S}$, Or or $\mathrm{W}+\mathrm{R}$. When data for does in the presence of a calf or yearling were analysed alone, time allocations were comparable to those obtained for all does; median percentages of time spent in $\mathrm{F}+\mathrm{S}, \mathrm{W}+\mathrm{R}$ and $\mathrm{Or}$ were 66,10 and 20 respectively (total time observed was $110 \mathrm{~min}$ ).

The data were also analysed for differences between study sites. For bucks, no differences were noted between behaviours in the 4 locations studied $(p=0.5$;

Table 1. Percent time (means $\pm \mathrm{SE}$ ) spent on different categories of behaviour in bucks and does observed concurrently: effects of interactions (females chased by males). F+ S-feeding plus searching, $\mathrm{Or}$ - orienting, $\mathrm{W}+\mathrm{R}$ - walking plus running, $\mathrm{N}$ - number of groups of animals, $n$ - number of $10 \mathrm{sec}$ observations. Observations made before chasing was initiated are included. ${ }^{a}$ Two bucks with one doe on one occasion, pairs of animals together on two occasions.

\begin{tabular}{|c|c|c|c|c|c|c|c|c|c|}
\hline & \multirow{3}{*}{$\mathrm{N}$} & \multicolumn{8}{|c|}{ Percent time spent on different behaviours } \\
\hline & & \multicolumn{4}{|c|}{ Bucks } & \multicolumn{4}{|c|}{ Does } \\
\hline & & $n$ & $\mathrm{~F}+\mathrm{S}$ & Or & $\mathrm{W}+\mathrm{R}$ & $n$ & $\mathrm{~F}+\mathrm{S}$ & Or & $\mathrm{W}+\mathrm{R}$ \\
\hline Chase & 9 & 524 & $34 \pm 10.2$ & $41 \pm 8.5$ & $28 \pm 7.2$ & 335 & $59 \pm 11.1$ & $26 \pm 7.6$ & $14 \pm 4.9$ \\
\hline No chase & $3^{\mathrm{a}}$ & 149 & $49 \pm 17.1$ & $35 \pm 12.8$ & $13 \pm 4.5$ & 137 & $73 \pm 7.3$ & $17 \pm 4.5$ & $10 \pm 3.6$ \\
\hline
\end{tabular}


Table 2. Male and female behaviours at different sites: time spent on each activity (percent $\pm \mathrm{SE}$ ) in areas A-D. Abbreviations as in Table 1. Activities failing to sum to $100 \%$ reflect time spent in other behaviours.

\begin{tabular}{lcccc}
\hline \multirow{5}{*}{ Behaviours } & \multicolumn{5}{c}{ Sites } \\
\cline { 2 - 5 } & A & B & C & D \\
\hline \multicolumn{5}{c}{ Bucks } \\
F+S & $26 \pm 14.0$ & $36 \pm 9.1$ & $46 \pm 13.5$ & $20 \pm 8.7$ \\
Or & $31 \pm 12.1$ & $37 \pm 9.9$ & $26 \pm 6.1$ & $41 \pm 9.0$ \\
W+R & $34 \pm 10.7$ & $15 \pm 7.7$ & $28 \pm 12.4$ & $38 \pm 8.6$ \\
N & 5 & 4 & 6 & 8 \\
& \multicolumn{5}{c}{ Does } \\
F+S & $71 \pm 8.3$ & $63 \pm 5.7$ & $73 \pm 4.5$ & $34 \pm 9.0$ \\
Or & $17 \pm 4.5$ & $24 \pm 3.7$ & $21 \pm 3.6$ & $27 \pm 8.1$ \\
W+R & $11 \pm 4.1$ & $11 \pm 4.3$ & $5 \pm 1.7$ & $39 \pm 8.8$ \\
N & 11 & 10 & 6 & 6 \\
\hline
\end{tabular}

Table 2), and equal proportions of time were spent on each behaviour. Does spent more time in $\mathrm{F}+\mathrm{S}$ than $\mathrm{W}+\mathrm{R}$ at sites $\mathrm{A}, \mathrm{B}$ and $\mathrm{C}$, and at these sites does spent more time than bucks in $\mathrm{F}+\mathrm{S}$, and less time in $\mathrm{W}+\mathrm{R}$. There were no differences in the proportions of time spent by does in each behaviour at site $\mathrm{D}$, and there were no significant differences between behaviours of does and bucks at this site. In the case of does, for differences both between and within sites, $p<0.001$ (Kruskal-Wallis ANOVA in both cases); multiple comparison (Dunn's test) showed $(p<0.05): \mathrm{W}+\mathrm{R}$ at $\mathrm{D}>\mathrm{W}+\mathrm{R}$ at $\mathrm{A}, \mathrm{B}$ or $\mathrm{C} ; \mathrm{F}+\mathrm{S}$ at $\mathrm{D}<\mathrm{F}+\mathrm{S}$ at $\mathrm{A} ; \mathrm{F}+\mathrm{S}>\mathrm{W}+\mathrm{R}$ at $\mathrm{A}, \mathrm{B}$ or $\mathrm{C}$. The low proportion of time spent in $\mathrm{F}+\mathrm{S}$ at site $\mathrm{D}$ may reflect the higher susceptibility of this site to disturbance.

\section{Discussion}

Bucks spent more time orienting and moving, does more time feeding and selecting food items during the rut. These differences were not affected by the presence of other individuals, and they applied to three of the four study sites used. The present data therefore confirm the difference predicted between bucks and does in time allocation during the rut and they support the premise that behaviour is influenced by factors determining reproductive success.

These conclusions differ from those of Turner (1979) who suggested that bucks and does spent equal times feeding. One important difference between this study and that of Turner (1979) is that the present observations were limited to the periods at dawn and dusk when the deer left the forest to feed on open ground. In contrast, Turner (1979) was able to observe animals throughout the day at most times of year, because of the open habitat he studied. The question therefore arises 
whether the disagreement between the present results and those of Turner (1979) reflects differences in behaviour between open agricultural and forested habitats. Differences in behaviour have been described between roe deer living in fields and those inhabiting forests (Kałuziński 1974, Bresiński 1982, Jeppesen 1990), the former adapting their daily feeding cycle to avoid men working in the fields, forming permanent social groups and using larger home ranges. Feeding behaviour may also be affected by a greater availability of forage in cultivated areas such as that studied by Turner (1979). Either of these conditions could have caused does to spend less time F+S and more time Or and W+R in Turner's (1979) study, and may have contributed to the differences between the study sites used here (Table 2).

Pregnancy rates exceed 90\% in most roe deer populations (Strandgaard 1972b, Loudon 1978), and any error resulting from inclusion of a small proportion of non-lactating does in the present study would be small. Furthermore does that were not feeding young might be expected to spend less time $\mathrm{F}+\mathrm{S}$ than those that were, given their lower energy requirement (Weiner 1975, Mauget et al. 1997), and on this basis their inclusion would be expected to obscure a difference between the sexes rather than contribute to it. Analysis of the behaviour of does with fawns or yearlings at foot confirmed that time budgeting was not affected by the presence of young.

No attempt was made here to discriminate between males that were holding territories and those that were not. However, this is unlikely to have resulted in a significant error. Young males occupy large home ranges encompassing the territories of several older males; they are harassed by territorial males and move $(\mathrm{W}+\mathrm{R})$ more than territorial males (Bramley 1970, Strandgaard 1972a), both in search of unoccupied territories and to avoid harassment. Therefore inclusion of non-territory holding males with females in this study would have obscured the difference between males and females, rather than contributed to it.

The roe deer is the only member of the Artiodactyla known to use embryonic diapause as a reproductive strategy. Instead of mating in the autumn and delivering young in the spring, as is the case for most temperate zone cervids, the roe doe mates during the summer and gives birth in the spring. For 5 months between the rut and early January roe deer blastocysts lie dormant in the uterus without undergoing implantation or embryonic development. Short (1981) suggested that this strategy offers bucks a period following the rut and before the onset of winter, during which they can recover body condition lost through rutting inappetance. The present findings confirm that, as predicted on the basis of optimal resource use, bucks spend less time feeding during the rut than does, and should therefore benefit to a greater extent than does from an opportunity to recover body condition in the autumn. However, lactating does have a considerably increased resting metabolic rate during the 3 months following parturition (Mauget et al. 1997) and so may also benefit from an early rut. The presence in dental cementum of layers of acellular material thought to reflect rutting 
inappetance in bucks or lactational stress in does (Aitken 1975) is consistent with this interpretation.

Acknowledgements: We thank Professor A. J. Ziecik (Institute of Animal Reproduction and Food Research, Polish Academy of Sciences) for providing accommodation and transport. The study could not have been completed without the generous assistance of Mr L. Twardowski (Deer Farm, Institute of Parasitology), Mr M. Ingielewicz (Forestry Administration Unit, Strzałowo, Poland) and Mrs M. K. Flint. We thank Professor A. S. I. Loudon and Dr V. Hayssen for commenting on the manuscript. This study was carried out while APFF was at the Institute of Zoology, London.

\section{References}

Aitken R. J. 1975. Cementum layers and tooth wear as criteria for ageing Roe deer (Capreolus capreolus). Journal of Zoology, London 175: 15-28.

Aulak W. and Babińska-Werka J. 1990. Use of agricultural habitats by roe deer inhabiting a small forest area. Acta Theriologica 35: 121-127.

Barth D., Giménes T., Hoffmann B. and Karg H. 1976. Testosteronkonzentrationen in peripheren Blut beim Rehbock (Capreolus capreolus). Zeitschrift für Jagdwissenschaft 22: 134-148.

Bateman A. J. 1948. Intra-sexual selection in Drosophila. Heredity 2: 349-368.

Bramley P. S. 1970. Territoriality and reproductive behaviour of roe deer. Journal of Reproduction and Fertility, Supplement 11: 43-70.

Bresiński W. 1982. Grouping tendencies in roe deer under agrocenosis conditions. Acta Theriologica 27: 427-447.

Byron H. 1981. Distribution patterns of roe deer (Capreolus capreolus) related to the availability of food and cover. Journal of Zoology, London 194: 271-275.

Cederlund G. 1981. Daily and seasonal activity pattern of roe deer in a boreal habitat. Viltrevy 11: 313-353.

Clutton-Brock T. H., Guinness F. E. and Albon S. D. 1982. Red deer: Behavior and ecology of two sexes. Edinburgh University Press, Edinburgh: 1-378.

Eisfeld D. 1977. Ernährungsphysiologie als Basis für die ökologische Beurteilung von Rehpopulationen. Review Suisse de Zoologie 83: 914-928.

Ellenberg H. 1978. Zur Populationsökologie des Rehes (Capreolus capreolus) L., Cervidae) in Mitteleuropa. Spixiana, Supplement 2: 1-211.

Jeppesen J. L. 1989. Activity patterns of free-ranging roe deer (Capreolus capreolus) at Kalø. Danish Review of Game Biology 13: 1-33.

Jeppesen J. L. 1990. Home range and movements of free-ranging roe deer (Capreolus capreolus) at Kalø. Danish Review of Game Biology 14: 1-14.

Kałuziński J. 1974. The occurrence and distribution of field ecotype of roe-deer in Poland. Acta Theriologica 19: 291-300.

Loudon A. S. I. 1978. The control of roe deer populations: a problem in forest management. Forestry 51: 73-83.

Martin P. and Bateson P. 1993. Measuring behaviour. An introductory guide. 2nd edn. Cambridge University Press, Cambridge: 1-222.

Mauget C., Mauget R. and Sempéré A. 1997. Metabolic rate in female European roe deer (Capreolus capreolus); incidence of reproduction. Canadian Journal of Zoology 75: 731-739.

Miquelle D. G. 1990. Why don't bull moose eat during the rut? Behavioral Ecology and Sociobiology 27: $145-151$.

Sempéré A. 1979. Territorial behaviour of the roe buck as determined by radio tracking: qualitative and quantitative analysis of territorial movements. [In: A handbook on biotelemetry and radiotracking. C. J. Amlauer and D. W. MacDonald, eds]. Pergamon, Oxford: 679-684. 
Short R. V. 1981. Discussion point. [In: Embryonic diapause in mammals. A. P. F. Flint, M. B. Renfree and B. J. Weir, eds]. Journal of Reproduction and Fertility, Supplement 29: 95.

Strandgaard H. 1972a. The roe deer (Capreolus capreolus) population at Kalø and the factors regulating its size. Danish Review of Game Biology 7: 1-205.

Strandgaard H. 1972b. An investigation of corpora lutea, embryonic development, and time of birth of roe deer (Capreolus capreolus) in Denmark. Danish Review of Game Biology 6: 1-22.

Trivers R. L. 1972. Parental investment and sexual selection. [In: Sexual selection and the descent of man. B. Campbell, ed]. Aldine, Chicago: 136-179.

Turner D. C. 1979. An analysis of time-budgeting by roe deer (Capreolus capreolus) in an agricultural area. Behaviour 71: 246-290.

Weiner J. 1975. Model of the energy budget of an adult roe deer. Polish Ecological Studies 1: 103-119.

Received 28 December 1996, accepted 4 July 1997. 